\title{
Educational Effects of International Team-Based Learning at Hokkaido University, Japan
}

\author{
Ken Saito ${ }^{1,}$, , Hirofumi Tani², Shotaro Imai ${ }^{1}$, Kaori Kuribayashi-Shigetomi ${ }^{1}$, Teruyuki \\ Tsuji ${ }^{1}$ \\ ${ }^{1}$ Institute for the Advancement of Higher Education, Hokkaido University, Japan \\ ${ }^{2}$ Faculty of Engineering, Hokkaido University, Japan
}

\begin{abstract}
Hokkaido University, Japan, has an international postgraduate programme called Nitobe School. One of the main features of this programme is that it accepts a wide range of both international and Japanese students belonging to various departments. This programme includes a course on the basics of team-based learning, in which the students learn mainly about team building and management, facilitation, project management, and presentation. After completion of this course in 2016, we conducted a survey to grasp the students' self-evaluation of their skill development. We found a tendency that both the Japanese and international students recognised the improvement in their team building and managing skills. Further, on the one hand, the Japanese students thought facilitation skills were the most useful, on the other hand, the international students believed team building and managing skills to be the most useful. Furthermore, both the Japanese and international students put project management skills as the second-most useful skills. Our study will help us understand the students' ways of thinking and their attitudes and provide us basic data for improving the curricula.
\end{abstract}

Keywords: Active learning, Facilitation, Postgraduate, Project management, Team building

\section{Introduction}

In 2014, the Ministry of Education, Culture, Sports, Science and Technology (MEXT) in Japan launched the Top Global University Project (TGUP), aimed at further advancing the initiatives of universities to develop top-level educational programmes for creating global leaders ${ }^{1}$. The TGUPs of 13 universities have been designated as Type A (top type).

Hokkaido University was founded as Sapporo Agricultural College in 1876 and has been developing as one of major comprehensive national universities since 1918. Under the TGUP, in 2015, Hokkaido University launched an international programme for postgraduate students called

1 https://tgu.mext.go.jp/en/index.html (20 February 2019) 


\section{International Conference On Advanced Research in EDUCATION}

\section{7-9 MARCH ,2019 London,United Kingdom}

Nitobe School ${ }^{2}$. One of the main features of Nitobe School is that it accepts both the international and Japanese students with diverse backgrounds and belonging to all the graduate schools (17 schools as of 2016). Currently, Nitobe School offers two programmes - the Basic Program mainly for master's course students and the Advanced Program for doctoral students. Every Hokkaido University postgraduate student can apply for Nitobe School and the applicants need to pass the entrance examination for the School. The capacity is approximately $120^{3}$ in the Basic Program and 25 in the Advanced Program.

The programmes aim to educate students to become global leaders with the requisite competencies such as team-based skills, problem-identification and problem-solving skills. Through the courses, the students are expected to acquire and develop the " $3+1$ competencies": (1) ability to attain sustainable personal development, (2) skills of team organisation and management, (3) capability of knowledge sharing and application for social benefit, and (+1) professional ethics.

The Basic Program adopts a quarter system from the Spring to Winter term. In the academic year of 2016, the programme consisted of four main courses: Start-up Course (Spring), Global Issue Course (Summer), Problem-solving Course (Fall), and Problem-finding Course (Winter) ${ }^{4}$. The whole programme aims at developing the students' abilities in identifying and solving interdisciplinary issues by cooperating with students having diverse expertise in a team.

The Start-up Course was designed for acquiring the basics of team-based learning ${ }^{5}$; the students learn mainly about building and managing teams, facilitating, managing projects, and acquiring presentation skills. In this study, we focus on the course offered in the Basic Program, with the aim of clarifying what kind of developments the students had recognised through the course. In the process, we will attempt to identify their needs as well.

2

'Nitobe' is named after Dr Inazo Nitobe (1862-1933), an alumnus of Sapporo Agricultural College, who contributed greatly to the international society as a writer and an Under-secretary General of the League of Nations. For background on the founding of Nitobe School and original concepts behind it, see Yamanaka and Shimamura (2017).

${ }^{3}$ Until the 2016 academic year, it was approximately 60 .

4

The study by Ravankar et al. (2017) provides useful information on the educational effects of the Problemsolving Course and the Problem-finding Course.

5

Imai et al. (2017) investigated how the instructors affected students' behaviours in team-based learning at Nitobe School. 


\section{International Conference On Advanced Research in EDUCATION}

\section{7-9 MARCH ,2019 London,United Kingdom}

\section{Methods}

\subsection{Outline of the Course}

In 2016, 78 students enrolled the Nitobe School Basic Program. Of them, 75 students registered for the Start-up Course. Their nationalities and affiliations were diverse as shown in Tabs. 1 and 2. For the purpose of analysis, we classified the students into two groups-Japanese students and international students. This is because in daily basis we, instructors, intuitively observe different attitudes and behaviours between the Japanese and international students. In order to understand them better and improve our curricula, we thought we could figure out the differences by our analysis. Therefore, we designed and implemented a survey for the students and compared the results of the two groups.

The main objectives of the course were (1) to teach basic ideas and skills required for team activities - communication, team building, facilitation, project management, presentation, etc.and (2) to teach the basic concepts of creating new knowledge and achieving outcomes in a team setup.

In order to realise these objectives, the contents of the course were designed with themes or modules as listed in Tab. 3. Each session was three hours long (having 2 parts of 90 min each) and consisted of lectures, group tasks, presentations, and reflections. Active learning methods were adopted in the classes. In the 2016 Start-up Course, although most of the lectures were conducted in Japanese with bilingual lecture materials, the students basically used English in other activities such as group tasks and presentations.

Table 1 Nationalities of Stu
\begin{tabular}{|c|c|}
\hline Nationality & $\begin{array}{l}\text { Numb } \\
\text { er }\end{array}$ \\
\hline Japan & $\mathbf{5 5}$ \\
\hline China & $\mathbf{1 4}$ \\
\hline Malaysia & $\mathbf{1}$ \\
\hline Myanmar & $\mathbf{1}$ \\
\hline Sri Lanka & $\mathbf{1}$ \\
\hline Kenya & $\mathbf{1}$ \\
\hline Zambia & $\mathbf{1}$ \\
\hline Madagasca & $\mathbf{1}$ \\
\hline r & $\mathbf{7 5}$ \\
\hline Sum &
\end{tabular}

Table 2: Affiliations of Students 


\section{International Conference On Advanced Research in EDUCATION}

7-9 MARCH ,2019 London, United Kingdom

Table 3: Contents of the course

\begin{tabular}{|l|l|} 
Graduate School & Numbe \\
\hline Letters & $\mathbf{r}$ \\
\hline Education & $\mathbf{3}$ \\
\hline Economics & $\mathbf{4}$ \\
\hline Law & $\mathbf{1}$ \\
\hline Public Policy & $\mathbf{4}$ \\
\hline $\begin{array}{l}\text { International } \\
\text { Media }\end{array}$ & $\mathbf{4}$ \\
\hline Science & $\mathbf{7}$ \\
\hline Chemical Sciences & $\mathbf{3}$ \\
\hline Life Sciences & $\mathbf{1 0}$ \\
\hline Agriculture & $\mathbf{1 0}$ \\
\hline Fisheries Sciences & $\mathbf{1}$ \\
\hline Engineering & $\mathbf{8}$ \\
\hline $\begin{array}{l}\text { Information } \\
\text { Science }\end{array}$ & $\mathbf{3}$ \\
\hline $\begin{array}{l}\text { Environmental } \\
\text { Science }\end{array}$ & $\mathbf{3}$ \\
\hline Medicine & $\mathbf{2}$ \\
\hline Health Sciences & $\mathbf{5}$ \\
\hline $\begin{array}{c}\text { Veterinary } \\
\text { Medicine }\end{array}$ & $\mathbf{1}$ \\
\hline
\end{tabular}

\begin{tabular}{|c|l|}
\hline Session & Theme \\
\hline \multirow{2}{*}{1} & Guidance \\
\cline { 2 - 3 } & Introducing yourself and others \\
\hline 2 & Self-promoting \\
\hline 3 & Team building \& facilitation \\
\hline 4 & Leadership \& facilitation \\
\hline 5 & Project management \\
\hline 6 & Project management \& prototyping \\
\hline 7 & Presentation \\
\hline 8 & Meeting mentors (Social awareness) \\
\hline
\end{tabular}




\section{International Conference On Advanced Research in EDUCATION}

\section{7-9 MARCH ,2019 London,United Kingdom}

In the first session, with icebreaking techniques utilised, the students formed a group of 4-6, learned to introduce him/herself and others effectively and attractively, and developed their communications skills through lectures and group tasks. In Session 2, they learned skills to introduce their team activities effectively to others. In other words, they learned about some techniques for self-promotion and public relations.

In Session 3, through lectures and group tasks, they learned about the process and settings of a team project, basic skills for an effective team task, methods for facilitation (identifying the mission, visualizing, using tools effectively, allocating the time, facilitating a discussion, etc.). In the next session, they learned about a leader, leadership and how a team works with leadership, while practicing how to facilitate and manage group discussions.

In Session 5, we invited special lecturers from Project Management Institute Japan to teach our students common knowledge of project management including a project, stakeholders, clarification of tasks, project planning, etc. The students were given a project on an urban design. In the following session, the students learned about risk management, and then put forward the team project with their urban design model prototyping. In Session 7, we gave a short lecture on how to make and prepare an effective presentation. Based on that, the students made a team presentation of their project.

In the last session, we held a Mentor Forum. The Nitobe School mentors, Hokkaido University alumni playing active roles internationally, shared their experiences in society with the students listening to their advice and exchanging opinions on careers in order to understand abilities required in society and cultivate social awareness. In 2016, the students had an opportunity to meet 8 mentors, however all of them were Japanese then.

Before learning at Nitobe School, most of the students are not accustomed to command these skills yet. They have a lot of opportunities to practise and develop the abovementioned skills in the Start-up Course. For example, to put forward a team project, they need to build and manage the team by utilising facilitation and communications skills. Thus, those skills taught at this course constitute basic abilities for efficient performance in a team. Based on those elementary skills, the students are required to identify and solve cross-disciplinary issues in the subsequent courses. Those students" efforts eventually contribute to developing their own " $3+1$ competencies".

\subsection{Questionnaire}

At the end of the course in 2016, we, the instructors, conducted an online survey (from 29 June to 4 July). The questionnaire consisted of 8 sections. A Japanese questionnaire and an equivalently translated English one were used in the survey. The students could choose which one to answer. Here is the whole list of the questions:

Q1. Are you satisfied with the Start-up course as a whole? Select one below: [(1)Very satisfied, (2)Satisfied, (3)Slightly satisfied, (4)Neither satisfied nor unsatisfied, (5)Slightly unsatisfied, (6)Unsatisfied, (7)Very unsatisfied.] 


\section{International Conference On Advanced Research in EDUCATION}

\section{7-9 MARCH ,2019 London,United Kingdom}

Write down the reason you select on the above question here.

Q2. As for abilities below, assuming your goal in each ability be 10 at your completion of graduate school, answer a grade for the ability you had before/after the course as a number shown below:

Q2-1b. Your communication ability [before the course]

Q2-1a. Your communication ability [after the course]

Q2-2b. Your ability in building and management of team [before the course]

Q2-2a. Your ability in building and management of team [after the course]

Q2-3b. Your facilitation ability [before the course]

Q2-3a. Your facilitation ability [after the course]

Q2-4b. Your project management ability [before the course]

Q2-4a. Your project management ability [after the course]

Q2-5b. Your presentation ability [before the course]

Q2-5a. Your presentation ability [after the course]

Q2-6b. Your understanding of abilities necessary for society [before the course]

Q2-6a. Your understanding of abilities necessary for society [after the course]

Q3. Answer the following questions:

Q3-1. How much do you think is the course as a whole useful for your learning? [(1)Very useful, (2)Moderately useful, (3)Slightly useful, (4)Not useful at all]

Q3-2. Which theme is most useful for you? Select at most two among the themes below: [(1) Icebreaker,

(2) Introducing yourself \& others, (3) Self-promotion, (4) Team building \& management, (5)

Facilitation, (6) Leadership, (7) Project management, (8) Prototyping, (9) Presentation, (10)

Developing social awareness, (11) Meeting mentors]

Q4. Write down any other contents or themes you would like to learn in the course, if any.

Q5. Write down any good points or those to be improved in the course, if any.

[Good points, Points to be improved]

Q6. Write down some other opinion or feedback to the course as a whole, if any.

Q7. Answer the questions on language.

Q7-1. What do you prefer on the language the instructors use in lecture, etc.? [(1)Mainly in Japanese, (2)Mainly in English, (3)Half in Japanese, half in English, (4)Gradually shifting from Japanese to English]

Q7-2. What do you prefer on the language you use in group work (team learning)? [(1)Mainly in Japanese, (2)Mainly in English, (3)Freely opting either Japanese or English, (4)Gradually shifting from Japanese to English]

Q7-3. What do you prefer on the language you give a presentation? [(1)Mainly in Japanese, (2)Mainly in English, (3)Freely opting either Japanese or English, (4)Gradually shifting from Japanese to English]

Q7-4. Write down the reason you select on the above questions:7-1,2,3.

Q8. Which kind of job would you like to take in the future? 


\section{International Conference On Advanced Research in EDUCATION}

\section{7-9 MARCH ,2019 London,United Kingdom}

The main purpose of the questionnaire was to grasp the students' self-evaluation of development and their needs for the course. In this case study, we focus on clarifying what kind of skills the students evaluated themselves as developed most during the course and which skills they found most useful. So, Q2 and Q3 are mainly discussed here.

Q2 was regarding how the students evaluated themselves as developed each ability they had learnt during the course. We listed 6 abilities which were taught in the abovementioned course: communication (Q2-1), team building and management (Q2-2), facilitation (Q2-3), project management (Q2-4), presentation (Q2-5), and understanding of abilities necessary for society (Q26). For example, in Q2-1, if a student marked '3' for 'before the course' (Q2-1b) and '7' for 'after the course' (Q2-1a), the difference would indicate that he/she developed the skill by 4 points during the course.

Q3 concerned what kind of skills the students regarded as most useful, so that we could grasp their needs on each skill they had learnt during the course.

\section{Results}

We received responses from 72 participants. They were all valid responses. However, two of them did not agree to the use of their data for the purpose of research. Thus, responses from 70 participants were available, and the overall response rate was 93.3 percent. Of the 70, 62 responded on the Japanese questionnaire and 8 on the English one. Further, of the 70 respondents, 50 were Japanese students and 20 were international students. They were accordingly classified into two groups-Japanese and international students.

\subsection{Developed Skills}

Q2 concerned how much the students evaluated they had developed each of the skills taught in the course. For each skill, the average score and the difference between the 'before the course' and 'after the course' scores were calculated.

First, Fig. 1 shows data for the Japanese students. For example, $1 \mathbf{b}$ and $1 \mathbf{a}$ indicate the average score given by the students for their communication skill before and after the course, respectively. The largest difference of 2.34 points $(=2 \mathrm{a}-2 \mathrm{~b})$ is observed for Q2-2 (team building and management). This is followed by a difference of 2.1 points $(=3 \mathrm{a}-3 \mathrm{~b})$ for Q2-3 (facilitation). The least difference of 0.96 points $(=5 \mathrm{a}-5 \mathrm{~b})$ was observed for Q2-5 (presentation), followed by 1.24 $(=1 \mathrm{a}-1 \mathrm{~b})$ for Q2-1 (communication). 


\section{International Conference On Advanced Research in EDUCATION}

\section{7-9 MARCH ,2019 London,United Kingdom}

Figure 1: Skills developed (Japanese students)

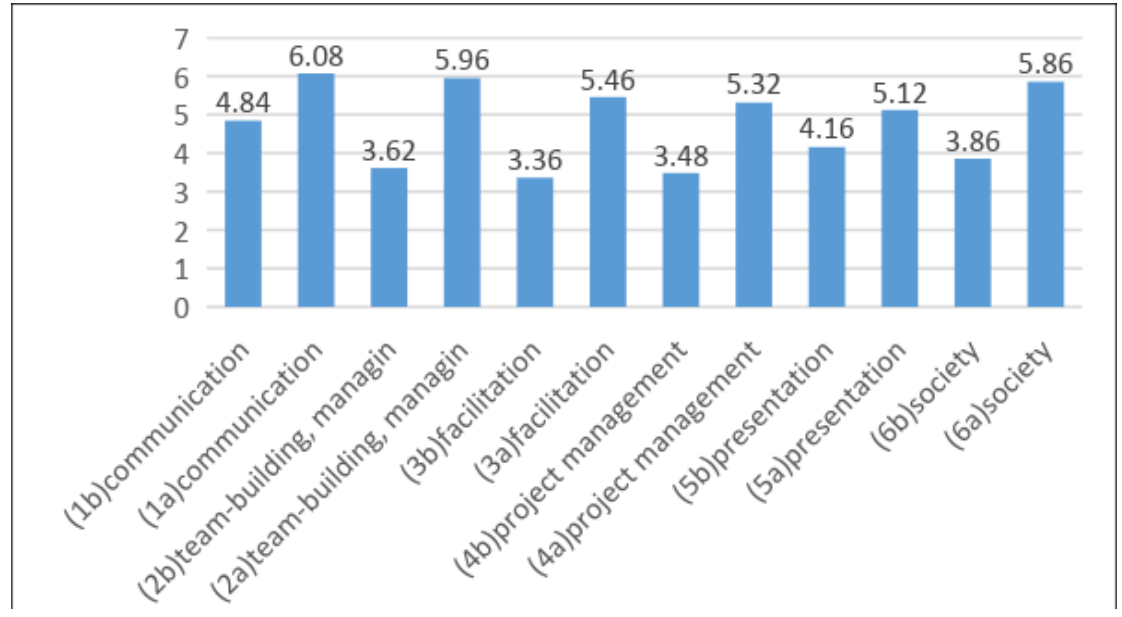

Next, Fig. 2 shows data for the international students. The largest difference of 2.2 points $(=2 \mathrm{a}-2 \mathrm{~b})$ is observed for Q2-2. The next highest at 1.95 points $(=4 \mathrm{a}-4 \mathrm{~b})$ is observed for Q2-4 (project management). The least difference of 1.35 points $(=5 \mathrm{a}-5 \mathrm{~b})$ is observed for $\mathrm{Q} 2-5$, followed by $1.5(=1 \mathrm{a}-1 \mathrm{~b})$ for $\mathrm{Q} 2-1$.

Figure 2: Skills developed (international students)

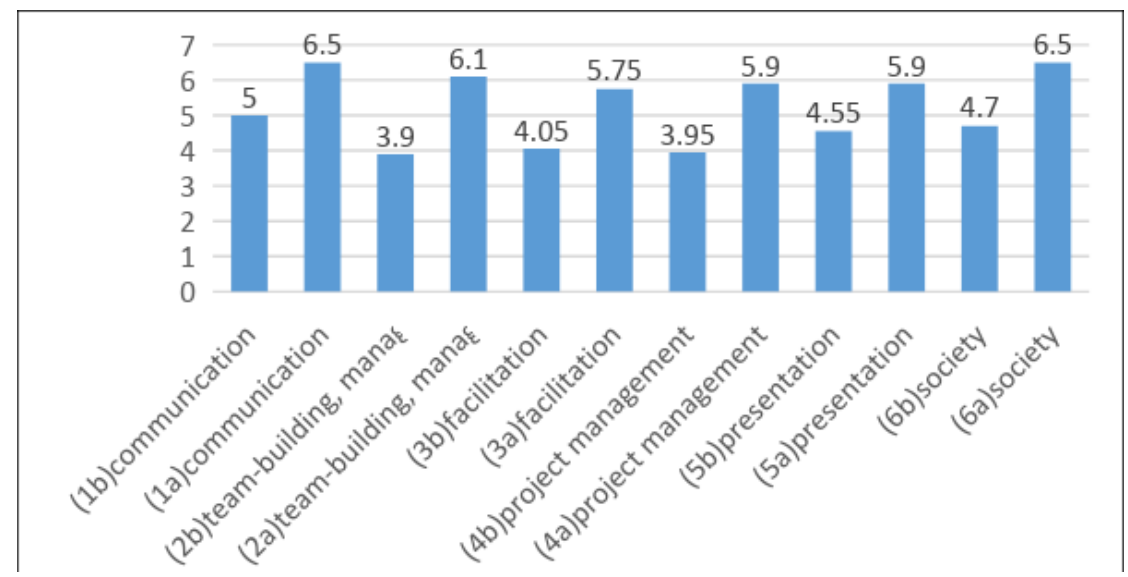

\subsection{Useful Skills}

As shown in Fig. 3, the Japanese students recognised that facilitation is the most useful themechosen by 26.0 percent of the students - covered in the course. This is followed by project management (24.0 percent) and meeting mentors (17.7 percent). 


\section{International Conference On Advanced Research in EDUCATION}

\section{7-9 MARCH ,2019 London,United Kingdom}

Figure 3: Useful skills (Japanese students)

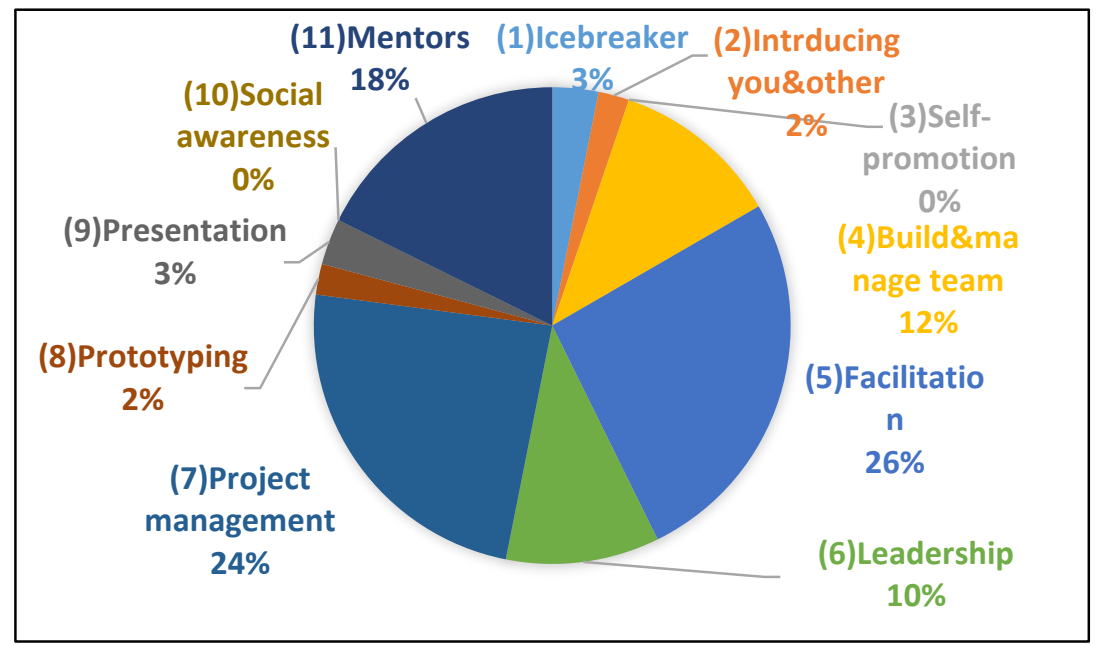

As shown in Fig. 4, the international students regarded team building and management as being the most useful for them (34.5 percent). This is followed by project management (20.7 percent), facilitation (10.3 percent), and icebreaker (10.3 percent).

Figure 4: Useful skills (international students)

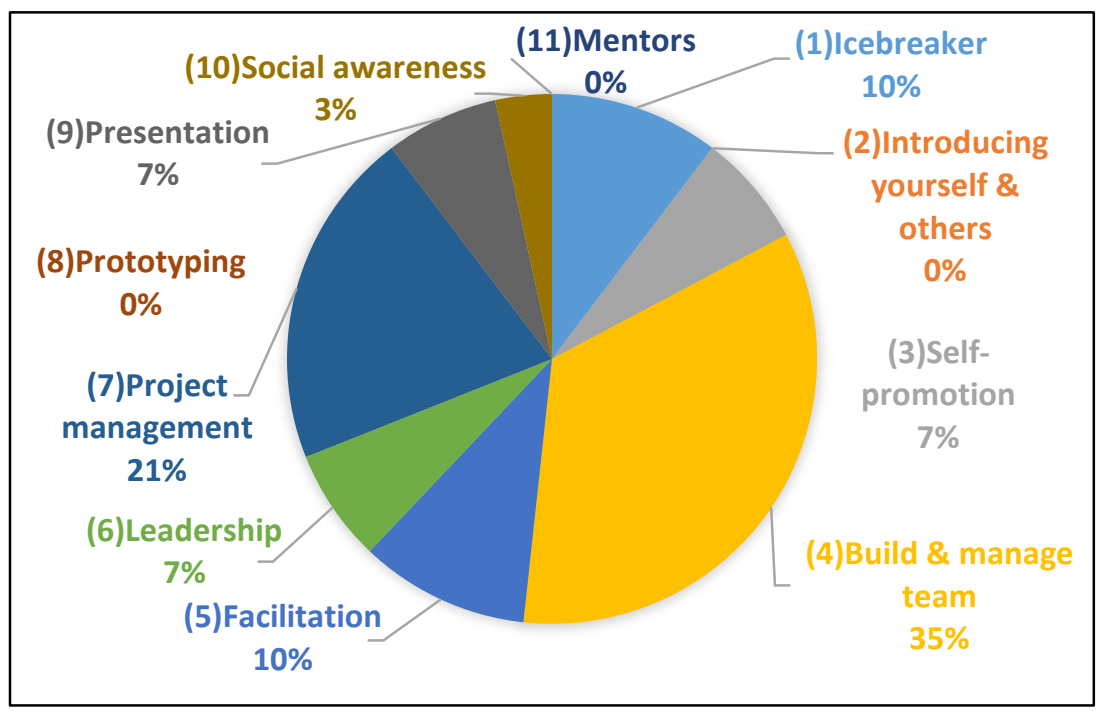

\section{Discussion}

We found that the Japanese students tended to recognise improvements in team building and managing and facilitation. Moreover, they responded that facilitation was the most useful skill, followed by project management. The international students too tended to identify team building and managing and project management as their improved skills. In addition, they considered team 


\section{International Conference On Advanced Research in EDUCATION}

\section{7-9 MARCH ,2019 London,United Kingdom}

building and management to be the most useful skill for them, with project management being the second most useful skill. We want to draw attention to the main similarities and differences between the responses of Japanese and international students about useful skills (Tab. 4).

Table 4: Useful skills compared

\begin{tabular}{|l|l|ll|l|l|}
\hline & $\begin{array}{l}\text { Project } \\
\text { manageme } \\
\text { nt }\end{array}$ & $\begin{array}{l}\text { Building } \\
\text { management } \\
\text { team }\end{array}$ & $\begin{array}{l}\text { \& } \\
\text { of }\end{array}$ & $\begin{array}{l}\text { Facilitati } \\
\text { on }\end{array}$ & $\begin{array}{l}\text { Meeting } \\
\text { mentors }\end{array}$ \\
\hline $\begin{array}{l}\text { Japanese } \\
\text { students }\end{array}$ & $24.0 \%$ & $11.5 \%$ & $26.0 \%$ & $17.7 \%$ \\
\hline $\begin{array}{l}\text { Internatio } \\
\text { nal } \\
\text { students }\end{array}$ & $20.7 \%$ & $34.5 \%$ & $10.3 \%$ & $\mathbf{0 . 0 \%}$ \\
\hline
\end{tabular}

Our data indicated that the Japanese and international students had different attitudes towards the skills they evaluated as developed during the course. For example, the Japanese students found such basic skills as facilitation to be the most useful, whereas the international students did not regard facilitation as a highly useful skill. Our observations of group activities in the course indicate the possibility that the international students are more accustomed to facilitate and moderate group tasks than the Japanese students.

The international students scored team building and managing skills three times higher than the Japanese students did. Most of the students were Japanese, so the ways of organising a meeting were likely to be in "Japanese style". Thus, the difference suggests that the international students may be interested in Japanese way of reaching a consensus in a meeting.

As the difference in the 'Meeting mentors' scores of the Japanese and international students shows, the latter might have wanted to listen to alumni other than Japanese. Based on the result, since the following year we have been inviting mentors from other countries who can talk about their international careers.

Both the Japanese and international students thought that project management skills were useful and developed in some degree during the course. The theory of project management is so comprehensive and systematic in the context of realistic issues in society that students can learn from it practical skills for managing a team, planning and implementing a project, etc. Based on this observation, for the academic year 2017, we redesigned our curriculum by incorporating more elements of project management, integrating team-based learning skills, and creating an independent course for students to mainly learn project management skills.

\section{Summary}

We conducted a survey to grasp the students' evaluation of their development of skills and their usefulness in a course for basics of team-based learning. The students tended to regard team 


\section{International Conference On Advanced Research in EDUCATION}

\section{7-9 MARCH ,2019 London,United Kingdom}

building and management skills as developed. The skills taught in the course consist of skills vital for further group tasks required in the subsequent courses at the Nitobe School Basic Program. In that respect, our course can be presumed to be effective to some degree.

We recognised some different attitudes between the Japanese and international students. For example, the Japanese students found such basic skills as facilitation to be the most useful, whereas the international students regarded team building and management as the most useful. Nevertheless, both of the groups evaluated project management skills as the second most useful and they seemed to develop the skills during the course.

In this way, we clarified some of the similarities and differences between the Japanese and international students in learning experience at Nitobe School. Although this case study focused on the students' subjective evaluation, the results indicate that our education seemed to make a certain positive influence on their learning experiences, especially on self-evaluations of skill developments.

\section{Acknowledgment}

Thanks go to, first, the Nitobe School students who participated in the survey, and Prof. Taro Yamauchi for directing the Start-up course in 2016 and Prof. Asami Shikida (Japan Advanced Institute of Science and Technology) for designing the course in 2015.

\section{References}

[1] Yamanaka, Y. and Shimamura, M. (2017). "Establishing the brand-new trans-graduate education frame: Challenges of Hokkaido University 'Nitobe School Program'," International Journal of Institutional Research and Management, vol. 1, no. 2, pp.37-53.

[2] Ravankar, A., Imai, S., Shimamura, M., Chiba, G. and Takasuka, T. (2017). "Problem-based learning and problem finding among university graduate students," Journal of Higher Education and Lifelong Learning, vol. 24, pp. 9-20.

[3] Imai, S., Ravankar, A., Shimamura, M., Takasuka, T., Chiba, G. and Yamanaka, Y. (2017). "Effect of instructor's actions and attitudes on student's motivation and discussion process in TBL class for graduate students," International Journal of Institutional Research and Management, vol. 1, no. 2, pp. 17-35. 